\title{
浅谈印尼邦加岛孔教徒对儒释道三教诸神的认识 \\ THE ANALYSIS OF CONFUCIAN FOLLOWERS' UNDERSTANDING OF GODS IN CONFUCIANISM, BUDDHISM, AND TAOISM IN BANGKA ISLAND - INDONESIA
}

\author{
Sugiato Lim \\ Chinese Department, Faculty of Humanities, BINUS University \\ Jln.Kemanggisan Ilir III No. 45, Kemanggisan-Palmerah, Jakarta Barat 11480 \\ qyetohayashi@yahoo.com
}

\begin{abstract}
Indonesia is a multi-ethnic, multi-culture, and multi-faith country. This piece of land combines a lot of ethnic elements into one. For example, Confucianism in Indonesia is combination of Confucianism, Buddhism, and Taoism characteristic in many ways. Aim of this paper is to find out the features of Confucianism as a religion or a belief for its followers in Bangka. In addition, this paper also focuses on finding out the followers view towards their Gods in their perspectives. In this article, classification of Gods in Confucianism, Buddhism, and Taoism is presented based on direct social observation. In this paper, analysis of Confucian followers understanding towards Gods in Confucianism, Buddhism, and Taoism in Bangka Island Indonesia is presented respectively. In conclusion, characteristics of these three religions have blended perfectly and there is no more distinction in Confucius, Buddhist or Taoism Gods in Confucian followers' community in Bangka Island.
\end{abstract}

Keywords: Gods of Confucianism-Buddhism-Taoism, Confucian followers, Bangka Island Indonesia

摘要

印尼是多民族、多文化、多信仰的国家。这片土地结合了许多民族元素于一体。以宗教信仰为例, 印尼孔教在很多方面非常到位地结合了儒释道三教特征于一体。本文针对孔教作为合法宗教, 在其信徒 心目中是占据一个什么样的地位。尤其关注邦加岛孔教徒对儒释道诸神的认识。本文以实地考察结果为 依据进行写作。作者也在此基础上对儒释道及其诸神进行归类。此外, 本文也分别从印尼邦加岛孔教徒 对儒、释、道三教诸神的认识进行分析、写作。最后, 作者得出, 印尼邦加岛孔教徒已经完美地将儒释 道元素熔于一炉。从他们对三教诸神的认识来看, 在信徒们意识中也没有再对儒释道诸神加以区分, 这 证明了三教元素完美地融合。

关键词: 儒释道诸神; 孔教徒; 印尼邦加岛 


\section{引言}

印尼在苏加诺执政时期曾经把孔教视为印尼国内合法宗教之一。在苏哈托长达三十余年的 统治下, 他对印尼华人采取了强制性的同化政策。关于当时印尼政府在文化方面对华人的同化, 主要表现在华文使用和教育、华人社团组织、华人文化习俗以及宗教信仰等方面。然而对印尼 人来说, 无论是原住民还是华人, 宗教信仰是生活当中不可缺少的元素之一。对当时的印尼华 人来说, 孔教就是他们对祖籍国的一种精神上的寄托和纽带。因此, 印尼华人为了争取孔教在 印尼的再度合法化, 长期以来坚忍不拔。直到苏哈托下台以后, 印尼历任总统瓦希德再度恢复 了印尼孔教的合法地位。由此可见, 孔教在印尼华人心中的地位之高。

然而, 在东南亚部分地区如马来西亚、印尼、新加坡等华人较为集中的国家, 儒、释、道 三教合一的现象是显而易见的。无论是从宗教仪式形式上看, 还是宗教的崇拜对象都非常到位 地把三教的特征融合在了一起。尤其在崇拜对象这一方面呈现出了多神论的特征, 甚至还带有 万物有灵论的迹象在内。既然如此，作者试图通过相关文献和亲身体验来进一步了解印尼邦加 岛孔教徒对儒释道三教诸神的认识。让我们更加认识印尼邦加岛孔教徒是以怎么样的一个心态 去信奉孔教以及印尼孔教的特点所在。

目前而言, 对印尼孔教的研究成果或许不少。但他们的研究范围和视角都是比较广泛的。 而本文的研究范围只限于印尼孔教徒和儒释道三教诸神。作者将从具有普遍性视角的老百姓的 思维立场来叙述民众信徒对儒释道三教诸神的认识。

\section{内容}

\section{儒释道及其诸神}

\section{儒教神明}

在儒教神明这一部分，本文将介绍印尼孔教徒对 “天” 的认识。也许会有人质问，为何不 对孔子反而对 “天” 进行介绍呢? 这是因为作者认为印尼孔教徒对 “天” 的认识远远多于他们 对孔子的认识。从日常生活便能发现, “天” 似乎已经渗透到了他们的精神上, 让他们时时刻刻 都要谨言慎行, 因为对他们而言 “天”就是至高无上的神。

\section{佛教神明}

不容置疑, 对印尼孔教徒而言, 观音菩萨乃是他们最为熟悉也是他们最为崇拜的佛教神明。 本文还将把印尼孔教徒对观音菩萨的认识和对阿弥陀佛以及释迦牟尼佛的认识做一个简单的比 较。 


\section{道教神明}

印尼孔教更具有趣味的部分是该宗教接纳了许多道教神明。而且是以民间传说中的道教神 明居多, 如: 福德正神、大伯公以及灶君。作者将在下文一一介绍印尼孔教徒对诸位神明的认 识。

\section{印尼孔教徒对儒释道三教神明的认识}

\section{对 “天” 的认识}

在印尼, 孔教也被称为孔夫子教。这个意思很显然就是孔子所创建起来的宗教。但本文为 何不对孔子进行介绍反而对 “天” 进行介绍呢? 这是因为作者认为印尼孔教徒对 “天” 的认识 远远多于他们对孔子的认识。甚至可以说, 许多印尼孔教徒不甚认识谁是孔子、孔子到底主张 什么。他们对孔子的认识更多的是来源于他们对 “孔教” 在字面上的认识。而 “天” 在他们的 认识里却占据了比孔子更为重要的地位。

在印尼的孔教里, “天” 就是其宗教的至高神, 相当于基督教里面所谓的上帝。印尼孔教所 谓的 “天” 包括了极为广泛的内涵在里面。不仅仅是方位意识上的天, 印尼孔教徒还认为祂是 世界上万事万物的主宰者, 祂明知人类所有的过去、现在和未来的一切。没有人能描述得清楚 祂到底长得怎么样, 但人们却很清楚衪是万事万物的真理。在每逢佳节时, 每个孔教徒都会在 自己家门前摆放香案祭天祀祖, 祈求全家平安、事业顺利、学业进步等。这种祭祀活动对他们 来说是必须的, 不然就是对 “天” 的大不敬, 但更多的是基于对 “天” 的一种带有功利性的心 态来进行祭祀的。这一现象与当时利玛窦对儒家的认识有明显的出入。在利玛窦看来: “儒家敬 奉的 “天” 是具自然哲学意义的, 并不存在超自然的神秘主义色彩, 不属于偶像崇拜。” 但对印 尼孔教徒来说, 他们对 “天” 的认识绝对不是像利玛窦所描述的那样。他们对 “天” 的态度也 不会像孔子本人对 “天” 的态度那样含糊。“天” 对他们来说确确实实已经演变成了一个具有浓 厚的宗教色彩的概念。

在日常生活中，我们很容易发现许多孔教徒经常把 “天” 挂在嘴边。我们最常听到的是他 们在劝告别人时会说: “天阿公有眼”, “天知, 骗不了天阿公”。在这所说的 “天阿公” 是人们 对 “天” 的另一种称法。在日常生活中, “天” 就这样渗透到了他们的精神世界, “天” 也成为 了他们最为熟悉的孔教的至高神。

\section{对佛教诸神的认识}

对印尼孔教徒而言，观音菩萨乃是他们最为熟悉也是他们最为崇拜的佛教神明。许多民众 也称之为观音娘。在每个孔教徒的家里去看, 我们会发现观音菩萨成为了他们最主要的供奉对 象之一。

人们都会害怕犯罪, 尤其在宗教观念里面所强调的罪过。在人们恐慌的内心里始终期望着 被赦免和得到救赎, 他们最怕的就是落入到痛苦的生活。在他们的认识里, 观音菩萨就是慈悲 的化身、闻声救苦的菩萨, 这种形象弥补了他们心中那恐慌和空荡的位子。在遇到困难的时候, 
他们首先想到的就是观音菩萨。到庙里去看的话, 我们会发现庙里供奉的观音神像不止一尊, 而且大小不一。大家最为熟悉的观音菩萨的形象有莲台观音、千手观音、手抱婴儿观音、竹篮 观音、御龙观音等。这几种形象在孔庙里一般都会以神像的形状被供奉。有些地区, 甚至还建 了专门的观音庙。由此可见, 观音菩萨在印尼孔教徒的心中的地位至高。

与此相比, 佛教其他诸佛菩萨, 如: 阿弥陀佛、释迦牟尼佛、药师佛、弥勒佛、地藏菩萨、 文殊菩萨、普贤菩萨等却没有太受到孔教徒的青睐。作者认为这与印尼孔教徒的人生观有关。 普遍说来, 许多孔教徒对佛教所说的彼岸世界不太有兴趣。比起彼岸世界, 他们更重视如何过 好现实生活, 他们主张 “活在当下”。这种积极入世的观念和儒家思想确实非常吻合。但我们需 要明白这一点, 在东南亚一些国家, 观音菩萨的形象似乎已经泛化到了一个超出了佛教的领域, 衪已被视为儒释道三教所公认的神明。故观音菩萨能够被信徒所广泛地接受。

\section{对道教诸神的认识}

印尼孔教徒最为熟悉的道教诸神有福德正神、大伯公和灶君。首先我们先谈论他们对福德 正神的认识。在印尼的一些客家人较为集中的地区, 福德正神普遍被称为土地伯公。顾名思义 就是掌管地面的神明。土地伯公在信徒们心中的地位绝不亚于 “天” 和观音菩萨。有些信徒, 甚至会在自己家旁边专门建造一座福德祠, 也叫伯公庙。

信徒们对土地伯公的信仰基于多种目的。有人出于感激土地的养育之恩而信仰, 也有人出 于对现实生活的功利目的而供奉土地公。

我们会发现, 在日常生活中, 土地伯公的形象也到处可见。比如: 祖先坟墓后方都会有一 个小石碑上面写着 “后土” 或 “土神” 二字。对人们来说, 祖先是保护自家的神明。而祖先在 土中的坟墓是受土地伯公来掌管的, 所以在给祖先上香之前要先给土地伯公上香请安, 这是理 所当然的。此外, 每到春节、中元节和冬至节人们也会在自家的后门口祭拜土地伯公, 感激祂 一直以来的庇佑和祈求风调雨顺、祈求地面得安稳。就这样, 因为人们的生活离不开土地使得 他们对土地伯公的认识也很深入。

其次, 我们谈论孔教徒对大伯公的认识。这里所说的大伯公并不等于上面所说的土地伯公。 但如果要明确地说大伯公到底是谁, 他却没有一个统一的答案。孔教里所说的大伯公是一个比 较模糊的概念。如果试图问一个孔教徒来回答这个问题, 他会说大伯公就是神, 但祂既不是“天”, 不是观音菩萨也不是福德正神。虽然衪是一个极为模糊的概念, 但祂在人们的心中却有着不可 磨灭的地位。在一些地区人们甚至不把孔庙叫做孔庙, 而是用大伯公庙来称呼孔庙。在家里, 许多信徒会在墙上贴一块红纸，上面写着 “大伯公之神位”; 再摆放一张桌子，上面摆着观音菩 萨神像和神祖牌, 就这样把大伯公、菩萨和祖先在同一时间当作供奉的对象。虽然如此, 人们 仍然很难说出大伯公到底是谁，也很难确定大伯公的具体概念到底是什么。

最后, 我们看一下孔教徒对灶君的认识。对许多孔教徒来说, 他们不明确灶君的历史传说, 但在他们的心中灶君有着不可替代的地位。以印尼邦加岛的孔教徒为例, 几乎每个家庭的厨房 里都有一个供奉灶君的神拿, 而且信徒们都会在每天上午和下午向灶君上香。因为灶君在他们 的认识里不光是饮食之神, 祂还是火神。人们每一天的生活不能没有火。做饭烧菜都离不开火, “火” 在此代表了生命, 所以灶君的形象时时刻刻都留在人们的心中。甚至有些人在入住新房 
子之前得先请入㷴房的第一把火一—表示恭请火神灶君也入住新房, 借此仪式赋予新房子一种 生命的意义。可见, 灶君在孔教徒的心中有着不可替代的地位, 因为衪的存在和人们的日常生 活有着很密切的关系。

\section{结语}

综上所述, 印尼孔教的一大特点就是它很到位地结合了儒释道三教特征于一体，从印尼邦 加岛孔教徒多神化的崇拜对象就能看出这一点。他们把儒家对 “天” 的概念与佛道两教的诸神 进行结合, 并同时成为了他们的崇拜对象。这一点淋漓尽致地体现出了东南亚华人较为集中的 地区，他们的孔教信仰在很大程度上是以三教合一的形式来发展的。

在印尼, 我们有时候很难分明一个人的宗教归属。有的人甚至声明自己既是孔教徒也是佛 教徒, 但同时在他家门前也挂着太极八卦图用来避邪。这一点也证明了印尼孔教徒对儒释道三 教诸神的分界线不甚分明。即使他们对一些神明不甚了解, 但他们确确实实已经把这些跨宗教 的神明纳入到自己的信仰里去, 并且是以十分崇敬的心态去对待每一位神明。

此外我们也不难发现, 这些为大家所熟悉的神明大部分是以民间神明为主。这也表明了他 们对现实生活的重视和态度的认真。从他们选择了比较生活化的神明作为崇拜对象来看, 这种 积极入世、世俗化的生活方式非常符合儒家思想。作者认为, 这一点也是印尼孔教徒的一大特 点之一。

\section{参考文献}

吉原和男 2009 , 《东南亚华人德教述论一一儒教为切入点》, 《思想战线》第 5 期第 35 卷。

刘海燕, 郭丹 2009 , 《闽台客家宗教与文化》, 福州: 福建人民出版社。

刘小枫 2007，《儒教与民族国家》，北京：华夏出版社。

卿希泰，唐大潮 2006，《道教史》，南京：江苏人民出版社。

乌丙安 2007，《中国民间神谱》，沈阳：辽宁人民出版社。

谢桃坊 2010 , 《儒家与宗教——轮西方的儒教观念及相关的问题》, 《西华大学学报》第 29 卷第 2 期。 
休斯顿・史密斯 2006, 《人的宗教 (修订版)》, 海口: 海南出版社。

张禹东 2000 , 《印度尼西亚全面同化政策下的华人宗教文化》，《华侨大学学报》第三期。

新华网 2010 年 2 月, 印尼雅加达举行大伯公游行欢庆元宵佳节：2011 年 12 月 20 日 http://news.xinhuanet.com/world/2010-02/28/content_13070751.htm 